\title{
VIII. On the signs exhibited by animals which indicate changes of the weather, with remarks on other prognostications
}

\section{Toaldo}

To cite this article: M. Toaldo (1799) VIII. On the signs exhibited by animals which indicate changes of the weather, with remarks on other prognostications, Philosophical Magazine Series 1, 4:16, 367-375, DOI: 10.1080/14786449908677090

To link to this article: http://dx.doi.org/10.1080/14786449908677090

巴n Published online: 25 Jan 2010.

Submit your article to this journal $\square$

Џ Article views: 2

Q View related articles ¿ 
acrols fomewhat obliquely before, and conical towards the tail. As the patient, before the fell ill, had ufed a great deal of milk and cheefe, $M$. Wilke was of opinion, that fome of the eggs of thefe flies had been conveyed into her ftomach in the rind of the cheefe.

VIII. On the Signs exbibited by Animals wbich indicate Changes of the Weatber, with Remarks on other Prognofications. By M. TOALDo*.

$\mathrm{T}$

HE fluids and folids of organifed beings, and their animal machines, are conftructed in fuch a manner that a certain degree of motion puts them in a good ftate, while an augmentation or diminution of it deranges and deftroys that ftate. The fluids, which by their nature are eafily moved, as well as the fibres, which are highly fufceptible of irritation, are readily affected by changes of the furrounding atmofphere, and fuffer from their impreffions, whether the air varies in its weight or qualities, or is changed in regard to its elafticity. We find, among thofe who are found and in perfect health, vivacity, good firits, and great agility, when the air is pure and elaftic; on the other hand, when the air becomes light and damp, and is deprived of its elafticity, it throws the body into a fate of languor and debility. Valetudinarians, whofe conftitutions are delicate, or who are advanced in life, are much fooner fenfible of the impreffions occafioned by changes of the weather than thofe who are ftrong and robuft. In general the fenfes of men, who in their way of life deviate from the fimplicity of nature, are coarfe, dull, and void of energy. Thofe alfo who are diftracted by a thoufand other objects, fcarcely feel the impreffions of the air; and if they fpeak of them to fill up a vacuum in their miferable and frivolous converfation, they do it without thinking of their caufes or effects, and without

* Foon his Metcorological Efays. 
ever paying attention to them. But animals which retain their natural inftinet, which have their organs better confituted and their fenfes in a more perfect ftate, and which befides are not changed by vicious and depraved habits, perceive fooner, and are more fufceptible of the impreffions produced in them by variations of the atmofphere, and fooner exhibit figns of them.

Until the new difcovery of animal electricity little at tention was paid to thefe figns, which were confequently afcribed to a certain natural prefcience. But as the electric matter iffuing from the earth diffufes itfelf through the atmofphere, it muft penetrate and agitate the frail machines in queftion; and as it carries with it vapours and exhalations of various kinds, thefe muft produce, on machines fo delicate, different fenfations, which make them move in a different manner; and, according as the received impreflion is agreeable or troublefome, they exhibit figns of joy or fadnefs; fend forth cries, or are filent; move, or remain at reft; as is obferved in all kinds of animals, without excepting man, when the weather is about to change.

In the laft place, internal and animal electricity, which in all probability is the agent of life and the grand fource of organic motion, mult be as much fubject to modifications as the external electricity, from which it acquires new force and activity by the vapours and hamidity of the atmofphere, which abforbing the electric matter in abundance, or ferving it as a conductor, draws it off from the animal machine. Hence arifes that languor and debility which are experienced during wet weather and when the fouth winds prevail; and for the fame reafon the moifture which has penetrated the organs, at leaft thofe that are weak or have fuffered any hurt or injury, or been expofed to fome new agitation, produces uneafinefs and occafions pain. It is difficult to explain clearly and with precifion how all this takes place; that is, how the electricity is excited, and by what mechanifm exhalations and vapours affect animals, and pro- 
fiuce changes in their bodies, fince we are not acquainted with the curious organifation of the moft delicate parts of thefe machines; but we can obferve and perceive the progrefs and general confequences of thefe phenomena, as well as of thofe by which they are produced. The following are the common and familiar figns exhibited by animals, which indicate changes of the weather, and which are not taken fo much from the agricultural poet, who firft collected them; as from common obfervation :

I. When the bats remain longer than ufual abroad from their holes, fly about in greater numbers and to a greater diftance than common, it announces that the following day will be warm and ferene; but if they enter the houfes, and fend forth loud and repeated cries, it indicates bad weather.

2. If the owl is heard to fcream during bad weather, it announces that it will become fine.

3. The croaking of crows in the morning indicates fine weather.

4. When the raven croaks three or four times, extending his wings and thaking the leaves, it is a fign of ferene weather.

5. It is andication of rain and ftormy weather when ducks and geefe fly backwards and forwards; when they plunge frequently into the water, or begin to fend forth cries and to fly about.

6. If the bees do not remove to a great diftance from their hives, it announces rain; if they return to their hives before the ufual time, it may be concluded that it will foon fall.

7. If pigeons return flowly to the pigeon-houfe, it indicates that the fucceeding days will be rainy.

8. It is a fign of rain or wind when the fparrows chirp a great deal, and make a noife to each other to affemble.

9. When fowls and chickens roll in the fand more than ufual, it announces rain: the cafe is the fame when the cocks crow in the evening, or at uncommon hours.

Vou. IV.

$\mathrm{B} \mathrm{b}$

10. Pea. 
10. Peacocks, which cry during the night, have a prefenfation of rain.

II. It is believed to be a fign of bad weather when the fwallows fly in fuch a manner as to bruth the furface of the water, and to touch it frequently with their wings and breaft.

12. The weather is about to become cloudy, and to change for the worfe, when the flies fting, and become more troublefome than ufual.

13. When the gnats collect themfelves before the fetting of the fun, and form a fort of vortex in the thape of a column, it announces fine weather.

14. When fea-fowl and other aquatic birds retire to the fea-fhore or marthes, it indicates a change of weather and a fudden ftorm.

15. If the cranes fly exceedingly high, in filence, and ranged in order, it is a fign of approaching fine weather; but if they fly in diforder, or immediately return with cries, it announces wind.

16. When the dolphins fport and make frequent leaps, the fea being tranquil and calm, it denotes that the wind will blow from that quarter from which they proceed.

17. If the frogs croak more than ufual; if the toads iffue from their holes in the evening in great numbers; if the earth-worms come forth from the earth, and fcorpions appear on the walls; if the ants remove their eggs from their fmall hills; if the moles throw up the earth more than ufual; if the affes frequently thake and agitate their ears; if the hogs fhake and fpoil the ftalks of corn; if the bats fend forth cries, and fly into the houfes; if the dogs roll on the ground, and fcratch up the earth with their fore-feet; if the cows look towards the heavens, and turn up their noftrils as if catching fome fmell; if the oxen lick their fore-feet, and if oxen and dogs lie on their right fide; all thefe are figns which announce rain.

18. The cale is the fame when animals crowd together. 
r9. When goats and theep are more obftinate and more Elefrous to crop their paftures, and feem to quit then with reluctance; and when the birds return flowly to their neits. rain may foon be expected.

\section{Otber Signs zubicb announce Changes of the Weatber.}

$r$. If the flame of a lamp crackles or flares, it indicates rainy weather.

2. The cafe is the fame when the foot detaches itfelf from the chimney and falls down.

3. It is a fign of rain, alfo, when the foot collected around pots or kettles takes fire in the form of fmall points like grains of millet; becaufe this phenomenon denotes that the air is cold and moift.

4. If the coals feem hotter than ufual, or if the flame is more agitated, though the weather be calm at the time, it indicates wind.

5. When the flame burns fteady, and proceeds ftraight upwards, it is a fign of fine weather.

6. If the found of bells is heard at a great diftance, it is a fign of wind, or of a change of weather.

7. The hollow found of forefts; the murmuring noife of the waves of the fea; their foaming, and green and black colour, announce a ftorm.

8. Good or bad fmells, feeming as if it were condenfed, are a fign of a change of weather; either becaufe exhalations arife and are difperfed in more abundance, which is a fign of an increafe of electricity; or becaufe the air does not difpell or raife thefe exhalations, which indicates that the conftitution of the atmofphere is motionlefs, light, and void of elafticity.

9. When the fpiders webs and the leaves of the trees are agitated without any fenfible wind, it is a fign of wind, and perhaps of rain; becaufe it denotes that ftrong and penetrating exhalations arife from the earth.

ro. Thefe figns are lefs equivocal when the dry leaves and chaff are agitated in a vortex, and raifed into the air. 
Ir. A frequetit change of wind, accompanied with an agitation of the clouds, denotes a fudden ftorm.

I2. A want or too great a quantity of dew being a mark of a ftrong evaporation, announces rain: the cafe is the fame with thick, white hoar-froft, which is only dew congealed.

13. If falt, marble, and glafs become moift fome days before rain; if articles' of wood, doors, and chefts of drawers fwell; if the corns on the feet and the fcars of old wounds become painful; all thefe figns indicate that aqueous vapours are exhaled from the earth, and are no doubt directed by the electric matter, which diffufes itfelf then in greater abundance and penetrates every body. Hence it happens that ftones become moift, that wood fwells, and falt becomes deliquefcent by the moifture. When the ftones after being moift become dry, it is a fign of fine weather.

I4. On the other hand, when the weather inclines to rain, the water is feen to diminifh in vafes and fountains, becaufe the humidity is then carried away by the evaporation of the electric matter.

I5. It is certainly a furprifing phenomenon to fee the earth, after very long and very abundant rains, to be fometimes almoft dry, the roads quite free from dirt, and the hands to become arid and parched. This is a fign that the rain has not altogether ceafed, and denotes a continual efflux of electric matter, which being renewed carries with it, in the form of vapours, all the moifture that falls on the earth.

16. There is fometimes, however, a great deal of dirt even after a very moderate rain, which in that cafe is a fign of fine weather, becaufe it indicates that evaporation has ceafed. Dry ftones and moift earth announce fine weather; dry earth and moift ftones announce rain.

17. The winds which begin to blow in the day-time, are much ftronger, and endure longer, than thofe which begin to blow only in the night.

18. Weather, whether good or bad, which takes place in 
the night-time, is ot, in general, of long duration; and, for the moft part, wind is more uncommon in the night than in the day-time. Fine weather in the night, with feattered clouds, doess not laft.

I9. A Venetian proverb fays, that a fudden ftorm from the north does not laft three days.

20. The hoar-froft, which is firft occafioned by the eaft wind, indicates that the culd will continue a long time, as was the cafe in $77 \%$.

21. If it thunders in the month of December, moderate and fine weather may be expected.

22. If it thunders at intervals in the fpring time, before the trees have acquired leaves, cold weather is ftill to be expected.

23. If the wind does not change, the weather will remain the fame.

Such almaft are the figns of the variations of the atmofphere; but I will not be anfwerable for the certainty of them all, Plutarch, in his Problems, where it is afked why a horfe who has efcaped from a wolf becomes fleeter, replies, that becaufe, by a fingle action, but executed with great force and yigour, he has acquired a difpofition to running and a habit of fpeed; or perhaps, becaufe he is naturally fwift and agile: but he adds, perhaps neither of thefe is true. This obfervation, I am afraid, will apply to fome of the vulgar prognoftics of the prefent day. For example, we are told, that it is a fign of fertility in any year when a fly is engendered in an acorn of that year; and that it is the fign of a pentilential year, if there iffues from it a fpider. Should the reafon be afked, it might be replied, that neither of thefe is true. I might venture to fay as much of thofe popular tales in regard to certain critical days of the month; yet we mult ftill have fome refpect for popular proverbs, which are often founded on obfervation and reafon. Thus jt is faid, that if it rains on the $3 \mathrm{~d}$ of May, the day of the Holy Crofs ; or on the ad of April, St, George's day; or the 
I5th of June, St. Vitus's day, \&c.; in the firft cafe the nuts will be fpoiled; in the fecond, the figs; and in the third, the grapes. All this may be true to a certain degree, that is to fay, when it rains for a certain number of days about thefe periods; becaufe, if rain falls at the time when fruittrees are in bloffom, it carries off the fecundating farina, and by thefe means renders them barren.

In regard to the general qualities of the feafons, and their influence, attention may be paid to the following figns :If the earth and air abound with infects, worms, frogs, locufts, \&c.; if the walnut-tree has more leaves than fruit; if there are large quantities of beans, fruit, and firh; if the fpring and fummer are too damp; if hoar-froft, fogs, and dew come on at times when they are not generally feen, the year will be barren : the oppofite figns announce fertility and abundance. Animals feem alfo to forefee and prognofticate fertility or barrennefs: it is faid that when the birds flock together, quit the woods and illands, and retire to the fields, villages. and towns, it is a fign that the year will be barren.

A great quantity of fnow in winter promifes a fertile year, but abundant rains give reafon to apprehend that it will be barren. A winter, during which a great deal of fnow and rain falls, announces a very warm fummer. It is generally believed that thunder and ftorms in winter prognofticate abundance, becaufe they fertilife the earth. When the fpring is rainy, it produces an abundant crop of hay and of ufelefs herbs, but at the fame time a fearcity and dearth of grain. If it is warm, there will be plenty, of fruit, but they will be almoft all fpoilt. If it is cold and dry, there will be few fruit or grapes, and filk-worms will not thrive. If it is only dry, there will be few fruit, but they will be good. In the laft place, if it is cold, the fruit will be late in coming to maturity.

If the fpring and fummer are both damp, or even both dry, a farcity and dearth of provifions is to be apprehended, 
If the fummer is dry, there will be little corn : difeafes will alfo prevail ; but they will be more numerous if it is warm. If it is moderately cold, the corn will be late; but there will be a great deal of it; and the feafon will occafion few difeafes.

A fine autumn announces a winter during which winds will prevail: if it is damp and rainy, it fpoils the grapes, injures the fown fields, and threatens a fcarcity. If it be too cold, or too warm, it produces many maladies. A long feverity of the feafons, either by winds, drought, dampnefs, heat or cold; becomes exceedingly deftructive to plants and animals. In general, there is a compenfation for rain or drought between one feafon and another. A damp fpring or fummer is commonly followed by a fine autumn. If the winter is rainy, the fpring will be dry; and if the former is dry, the latter will be damp. When the autumn is fine, the fpring will be rainy. That this alternation is in general verified may be feen in a Journal carried on for forty years, and formerly edited by M. de Poleni.

IX. On the Effects of Oil in Cafes of the Bite of Serpents; republifbed from the Cbarleftown (Soutb-Carolina) City Gazette*.

I Meffrs. Freneau and Paine,

READ with pleafure, in your paper of the 2Ift of November, "fome thort directions for the cure of the plague," compofed from a fmall pamphlet lately publifhed by Count Berchtold at Vienna, by the ufe of fweet alive oil.

To take off the fharp edge of misfortune, or to meliorate the condition of man, is a godlike employment. Count Berchtold will be defervedly claffed by the philanthropift among the benefactors to mankind.

In great cities, particularly in London, a number of per-

* From the American Medical Repofitory. 